\title{
Knowledge of Osteoporosis and Its Related Risk Factors among Nursing Professionals
}

\author{
Dr. A.H.M. Aktaruzzaman ${ }^{1 *}$, Dr. Afsar Ahammed ${ }^{2}$, Dr. Mst. Sabina Yasmin ${ }^{3}$, Dr. Md. Shafiqul Islam Dewan ${ }^{4}$
}

\author{
${ }^{1}$ Associate Professor, Department of Endocrinology, National Institute of Traumatology and Orthopedic Rehabilitation \\ (NITOR), Dhaka, Bangladesh \\ ${ }^{2}$ Assistant Professor, Department of Endocrinology, National Institute of Traumatology and Orthopedic Rehabilitation \\ (NITOR), Dhaka, Bangladesh \\ ${ }^{3}$ Assistant Registrars, Department of Endocrinology, National Institute of Traumatology and Orthopedic Rehabilitation \\ (NITOR), Dhaka, Bangladesh \\ ${ }^{4}$ Indoor Medical officer, Department of Endocrinology, National Institute of Traumatology and Orthopedic \\ Rehabilitation (NITOR), Dhaka, Bangladesh
}

DOI: $10.36347 /$ sjams.2020.v08i12.032

| Received: 08.12.2020 | Accepted: 19.12.2020 | Published: 29.12.2020

*Corresponding author: Dr. A.H.M. Aktaruzzaman

Abstract

Original Research Article

Introduction: Osteoporosis is rapidly assuming epidemic proportions in Bangladesh. Osteoporosis is defined as a systemic skeletal disorder characterized by low bone mass and micro architectural deterioration of bone tissue, with a consequent increase in bone fragility and susceptibility to fracture. Currently, it is estimated that over 200 million people worldwide have osteoporosis. This disease can be prevented by maintaining some precaution. Nursing professionals are the key link in the chain of multidisciplinary approach to the management of this potentially preventable disease, and in educating patients about the various aspects of its evaluation and management. So, to prevent and lessen osteoporosis, appropriate knowledge among nursing professionals is exigent. Aim of the study: The aim of this study was to find out the knowledge of Osteoporosis and its related risk factors among nursing professionals. Methods: This cross-sectional study was conducted in the Department of Endocrinology, National Institute of Traumatology and Orthopedic Rehabilitation (NITOR), Dhaka, Bangladesh during the period from September 2018 to September 2019. A self-administered questionnaire was selected as the tool of assessment to collect primary data from 123 nurses. The respondents needed to answer 20 questions regarding knowledge of osteoporosis and its related risk factors. There were 4 age groups which were 30-39, 40-49, 50-59 and >60.All these primary data were compiled on a master chart first, and then organized by using scientific calculator and standard statistical formula. Percentage was calculated to find out the proportion of the findings. Further statistical analysis of the results was done by computer software devised in the statistical packages for social scientist (SPSS-23) and MS excel. Result: After getting response from 123 nurses through a questionnaire we found that nursing professionals had moderate level of knowledge of osteoporosis and its related risk factors. There were many dimensions where the respondents lacked proper knowledge. Conclusion: Osteoporosis has been identified as one of the most important health problems of this century. But osteoporosis can be prevented or lessened by taking precautional measures. Nurses can play a great role to raise awareness among people. But many studies show that the do not have good knowledge about it. In our study we also found that nursing professionals do not have proper knowledge regarding osteoporosis and its related risk factors. So, training and educational program should be taken to increase their knowledge level.

Key words: Knowledge, Osteoporosis, Risk factors and Nursing professionals.

Copyright (C) 2020 The Author(s): This is an open-access article distributed under the terms of the Creative Commons Attribution 4.0 International License (CC BY-NC 4.0) which permits unrestricted use, distribution, and reproduction in any medium for non-commercial use provided the original author and source are credited.

\section{INTRODUCTION}

Osteoporosis is the disease of decreasing bone mass and structural deterioration of bone tissue, leading to an increased susceptibility to fractures [1]. The World Health Organization (WHO) has defined osteoporosis in terms of bone mass that is more than 2.5
SD below the mean for peak bone mass in healthy young adults [2]. Currently, it is estimated that over 200 million people worldwide have osteoporosis [3]. Osteoporosis has frequently been called a "silent disease", due to the fact that it is asymptomatic until a fracture occurs [4]. However, according to Edwards and Fraser, the disease is an apt way to describe the scant 
attention it has received, despite its being a disease associated with serious physical and psycho-social consequences [5]. Still many people are not conscious about osteoporosis and its related risk factors. The main risk factors related to osteoporosis includes inadequate nutritional absorption, lack of physical activity, less weight or small body structure, cigarette smoking, alcohol consumption, air pollution, stress, older age, gender, white ethnic background, prior fracture or fall, family history of osteoporosis, and not major but important factors are chronic use of certain medications (prolonged corticosteroid use, and so on), vitamin D deficiencyetc [6]. There have been many studies around the world about osteoporosis which showed that, many nursesdo not have proper knowledge about it [7-11]. This disease can be prevented or lessened by taking primary prevention steps by engaging in specific healthy behaviors, or through secondary prevention with screening and early diagnosis and treatment and raising awareness among the people [12]. Nursing professionals are the key link in the chain of multidisciplinary approach to the management of this potentially preventable disease, and in educating patients about the various aspects of its evaluation and management. The aim of the study was to find out the knowledge of osteoporosis and its related risk factors among nursing professionals.

\section{OBJeCTIVES}

The objective of the study was to evaluate the knowledge about osteoporosis and its related risk factors among nursing professionals.

\section{Methodology \& Materials}

This was a cross-sectional study and was conducted in the Department of Endocrinology, National Institute of Traumatology and Orthopedic Rehabilitation (NITOR), Dhaka, Bangladesh during the period from September 2018 to September 2019. There were 123 nurses participating in the study. There were 4 age groups which were 30-39, 40-49, 50-59 and $>60$. A questionnaire was provided among each participant and they gave answer to them. There were 20 questions in the questionnaire. All participants in the survey were provided with complete information regarding the questionnaire and informed that participation in the study was entirely voluntary. All these primary data were compiled on a master chart first, and then organized by using scientific calculator and standard statistical formula. Percentage was calculated to find out the proportion of the findings. Further statistical analysis of the results was done by computer software devised in the statistical packages for social scientist (SPSS-23) and MS excel-16.

\section{RESUlT}

In the study, we found that maximum respondents were in the age group of 30-39 which was
$41(33.33 \%)$, then the age group of 40-49 which was 33 $(26.83 \%)$, then age group of $50-59$ which was 29 $(23.58 \%)$, and the minimum respondents were in the age group of $>60$ which was 20 (16.26\%) (Table-I). To analyze the knowledge about osteoporosis from table-II, we found that from 123 respondents 107 (86.99\%) had knowledge about that men and women both can have osteoporosis, $81(65.85 \%)$ respondents had knowledge about physiopathology of osteoporosis, 60 (48.78\%) respondents had knowledge about symptoms of osteoporosis, $69(56.10 \%)$ respondents had knowledge about diagnosis and treatment of osteoporosis, and 98 (79.67\%) respondents had knowledge about prevention of osteoporosis. The study also showed the knowledge about the related risk factors of osteoporosis among nursing professionals (Figure I) From Figure I, we found that out of 123 respondents 84 (68.29\%) had knowledge about that inadequate nutritional absorption is a risk factor of osteoporosis, $83(67.48 \%)$ respondents had knowledge about that lack of physical activity is a risk factor, $38(30.89 \%)$ respondents had knowledge about that less weight or small body structure is a risk factor, $76(61.79 \%)$ knowledge about that cigarette smoking is a risk factor, $82(66.67 \%)$ respondents had knowledge about that alcohol consumption is risk factor, $72(58.54 \%)$ respondents had knowledge about that air pollution as a risk factor, 84 (68.29\%) respondents had knowledge about that stress is a risk factor, $115(93.50 \%)$ respondents had knowledge about that older age people are affected more, 102 (82.93\%) respondents had knowledge about female people have higher risk, $69(56.10 \%)$ respondents had knowledge about white ethnic background as a risk factor, 67 $(54.47 \%)$ respondents had knowledge about that prior fracture or fall is a risk factor, $93(75.61 \%)$ respondents had knowledge about that family history is a risk factor, $58(47.15 \%)$ respondents had knowledge about that chronic use of certain medications is a risk factor, 95 (77.24\%) respondents had knowledge about that is vitamin D deficiency a risk factor.

Table-I: Age distribution $(\mathrm{n}=123)$

\begin{tabular}{|l|l|l|}
\hline Age (years) & $\mathbf{n}$ & $\mathbf{\%}$ \\
\hline 30 years to 39 years & 41 & 33.33 \\
\hline 40 years to 49 years & 33 & 26.83 \\
\hline 50 years to 59 years & 29 & 23.58 \\
\hline$>60$ years & 20 & 16.26 \\
\hline Total & 123 & 100 \\
\hline
\end{tabular}

Table-II: Knowledge about Osteoporosis ( $=123)$

\begin{tabular}{|l|l|l|}
\hline Dimensions & $\mathbf{n}$ & $\mathbf{\%}$ \\
\hline $\begin{array}{l}\text { Men and women both can have } \\
\text { osteoporosis }\end{array}$ & 107 & 86.99 \\
\hline Physiopathology of osteoporosis & 81 & 65.85 \\
\hline Symptoms of osteoporosis & 60 & 48.78 \\
\hline $\begin{array}{l}\text { Diagnosis and treatment of } \\
\text { osteoporosis }\end{array}$ & 69 & 56.10 \\
\hline Prevention of osteoporosis & 98 & 79.67 \\
\hline Total & 123 & 100 \\
\hline
\end{tabular}




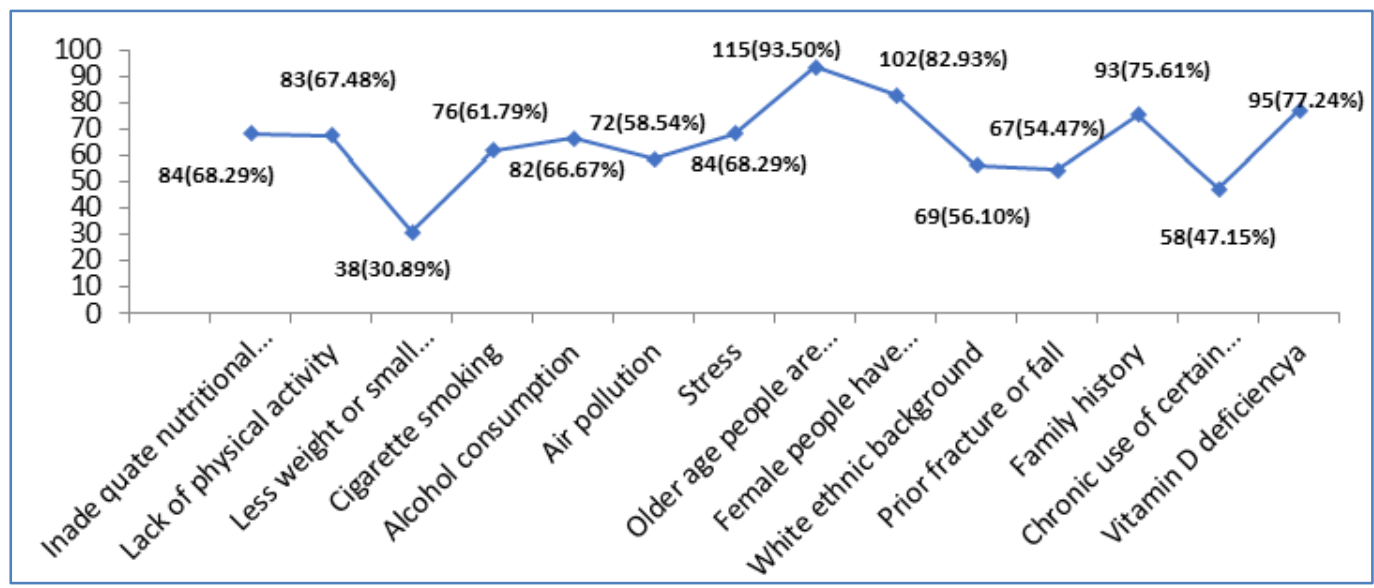

Fig-I: Risk factors related to Osteoporosis $(\mathrm{n}=123)$

\section{DISCUSSION}

Through this study we tried to find out the knowledge of osteoporosis and its related risk factors among nursing professionals. As nurses have a major responsibility to initiate as well as impart primary and secondary osteoporosis prevention education to patients and the public, the education of osteoporosis among them is very necessary. In the study we found that in terms of knowledge of osteoporosis, nurses had better knowledge about that men and women both can have osteoporosis and about the prevention of osteoporosis which was $107(86.99 \%)$ and $98(79.67 \%)$ respectively where knowledge about physiopathology of osteoporosis, knowledge about symptoms of osteoporosis, knowledge about diagnosis and treatment of osteoporosis were lower and which were 81 $(65.85 \%), 60(48.78 \%)$ and $69(56.10 \%)$ respondents respectively (Table-2). In terms of knowledge regarding related risk factors of osteoporosis, we found that respondents had better knowledge about that older age people are affected more, knowledge about female people have higher risk, knowledge about that is vitamin $\mathrm{D}$ deficiency a risk factor and knowledge about that family history is a risk factor which were 115 (93.50\%), 102(82.93\%), 95 (77.24\%) and 93 (75.61\%) respondents respectively. But their knowledge about other risk factors was poor. $84(68.29 \%)$ had knowledge about that inadequate nutritional absorption is a risk factor of osteoporosis, $83(67.48 \%)$ respondents had knowledge about that lack of physical activity is a risk factor, 38 (30.89\%) respondents had knowledge about that less weight or small body structure is a risk factor, $76(61.79 \%)$ knowledge about that cigarette smoking is a risk factor, $82(66.67 \%)$ respondents had knowledge about that alcohol consumption is risk factor, 72 (58.54\%) respondents had knowledge about that air pollution as a risk factor, $84(68.29 \%)$ respondents had knowledge about that stress is a risk factor, $69(56.10 \%)$ respondents had knowledge about white ethnic background as a risk factor, $67(54.47 \%)$ respondents had knowledge about that prior fracture or fall is a risk factor, 58(47.15\%) respondents had knowledge about that chronic use of certain medications is a risk factor.
Our finding was similar to those of Berarducci [13], Perez-Edo L, Ciria RM [14], Castelo-Branco Cand Hunt and Repa-Eschen [15]. All results indicated that there was moderate level of knowledge of osteoporosis. For instance, Berarducci figured a mean knowledge score of 14.62 out of a possible score of 22 among senior nursing students [13]. Perez-Edo et al. found a correct answer rate of $63 \%$ among primary care practitioners [14]. the knowledge of 22 of 27 in specific topics among RNs were identified and evaluated as less than adequate by Hunt and Repa Eschen [15].

\section{Limitations OF THE STUDY}

Our study wasn't a blinded study so patient bias was present along with observer bias in subjective recording and was a single center study, blinding was not done, short follow up period. If the sample was larger, the result could have been more accurate. Moreover, the questionnaire did not allow for subjects to elaborate on their views and answers, and demographic data such as social status, years in service and disciplines was not collected.

\section{Conclusion and Recommendations}

Osteoporosis has been identified as one of the most important health problems of this century. People are getting affected by it increasingly. But osteoporosis can be prevented or lessened by taking precautional measures. Nurses can play a great role to raise awareness among people. But along with many studies, from our study we also found that nursing professionals do not have proper knowledge regarding osteoporosis and its related risk factors. So, training and educational program should be taken to increase their knowledge level.

Funding: No funding sources

Conflict of interest: None declared

Ethical approval: The study was approved by the Institutional Ethics Committee 


\section{REFERENCES}

1. Pande KC, de Takats D, Kanis JA, Edwards V, Slade P, McCloskey EV. Development of a questionnaire (OPQ) to assess patient's knowledge about osteoporosis. Maturitas. 2000 Dec 29;37(2):75-81.

2. Cummings SR, Black D. Bone mass measurements and risk of fracturein caucasian women: A review of findings from prospective studies. The American journal of medicine. 1995 Feb 27;98(2):24S-8S.

3. Cooper C, Melton III LJ. Epidemiology of osteoporosis. Trends in Endocrinology \& Metabolism. 1992 Aug 1;3(6):224-9.

4. Hamdy RC. Osteoporosis, the deafening silent epidemic. South Med J. 2002; 95:567-568.

5. Edwards L, Fraser M. 10 How do we increase awareness of osteoporosis?. Baillière's clinical rheumatology. 1997 Aug 1;11(3):631-44.

6. Pouresmaeili F, Kamalidehghan B, Kamarehei M, Goh YM. A comprehensive overview on osteoporosis and its risk factors. Therapeutics and clinical risk management. 2018; 14:2029.

7. Berarducci A, Lengacher CA, Keller R. The impact of osteoporosis continuing education on nurses' knowledge and attitudes. The Journal of Continuing Education in Nursing. 2002 Sep 1; 33(5):210-6.

8. Giangregorio L, Fisher P, Papaioannou A, Adachi JD. Osteoporosis knowledge and information needs in healthcare professionals caring for patients with fragility fractures. Orthop Nurs. 2007; 26:27-35.

9. Goh ML, Singh RU, Vauski S. Knowledge of risk factors and current health practices of orthopaedic unit nurses in the prevention of osteoporosis. Singapore Nursing Journal. 2001; 28:17-25.

10. Ziccardi SL, Sedlak CA, Doheny MO. Knowledge and health beliefs of osteoporosis in college nursing students. Orthop Nurs. 2004; 23:128-33.

11. Zhang RF, Chandran M. Knowledge of osteoporosis and its related risk factors among nursing professionals. Singapore medical journal. 2011 Mar 1;52(3):158-62.

12. Renfro J, Brown JB. Understanding and preventing osteoporosis. Am Assoc Occup Health Nurse. 1998; 46:181-189.

13. Berarducci A. Senior nursing students' knowledge of osteoporosis. Orthop Nurs. 2004; 23:121-127 22.

14. Pérez-Edo L, Recasens MC, Castelo-Branco C, López PO, Marqués AG, Pérez C, Dalmau JM. Management of osteoporosis in general practice: a cross-sectional survey of primary care practitioners in Spain. Osteoporosis international. 2004 Mar 1; 15(3):252-7.

15. Hunt AH, Repa-Eschen L. Assessment of learning needs of registered nurses for osteoporosis education. Orthopaedic nursing. 1998 Nov 1; 17(6):55. 